\title{
Secondhand smoke and respiratory ill health in current smokers
}

\author{
T-H Lam, L-M Ho, A J Hedley, P Adab, R Fielding, S M McGhee, G M Leung, L Aharonson-Daniel
}

Tobacco Control 2005;14:307-314. doi: 10.1136/tc.2005.011775

See end of article for authors' affiliations .....................

Correspondence to: Dr Lai-Ming Ho, Department of Community Medicine, The University of Hong Kong, 21 Sassoon Road, Pokfulam, Hong Kong; Imho@hkucc.hku.hk

Received 8 March 2005 Accepted 29 June 2005

\begin{abstract}
Background: Numerous studies have concluded that secondhand smoke (SHS) is harmful to non-smokers but controversy persists regarding its effects on smokers. The impact of SHS exposure on the acute respiratory health of current active smokers was examined using a cross sectional design.

Methods: 9923 uniformed staff in the Hong Kong Police Force completed a standardised questionnaire on current and past smoking, SHS exposure at home and at work, acute respiratory symptoms, and recent physician consultation. 3999 male current smokers were included in the analysis.

Results: About $5 \%$ of the smokers were exposed to SHS at home only, $53 \%$ were exposed at work only, and $30 \%$ were exposed both at home and at work. The prevalence ratios for respiratory symptoms (throat and nasal problems, cough, phlegm, and wheeze), physician consultation, and self medication were higher for those who were exposed to SHS at home or at work. The odds ratios of reporting one or more respiratory symptoms, for SHS exposures at home or at work, were $1.33195 \%$ confidence interval (CI) 1.12 to 1.59$)$ and $1.66(95 \% \mathrm{Cl} 1.36$ to 2.02$)$ respectively, after adjusting for age, marital status, education, rank and duties, exposure to self perceived dusty or polluted environment in previous job, and total dose of active smoking. The adjusted odds ratios showed significant positive dose-response gradients with SHS exposure at home, at work, and at both places combined.

Conclusions: SHS exposure is strongly associated with increased acute respiratory symptoms and recent outpatient service utilisation in current smokers. If the association is causal, public health action to limit SHS exposure could also benefit smokers.
\end{abstract}

A lthough secondhand smoke (SHS) or environmental tobacco smoke has been shown to be a class 1 human lung carcinogen ${ }^{1}$ and a causal factor for heart disease in adults and respiratory ill health in both children and adults, ${ }^{2}$ most of the evidence has been derived from studies on non-smokers. Sidestream smoke is qualitatively different from and more toxic than mainstream smoke. ${ }^{3}$ Few studies have examined the adverse effects of SHS exposure among active smokers, although smokers are at least equally if not more exposed to SHS from other smokers nearby. Our Medline search from January 1983 to October 2004 using the criteria "passive or second-hand or second-hand or involuntary; smok\$ or tobacco\$ or cigarette\$" and "active smoker\$ or passive smoker\$" (\$ indicates one or more characters) yielded only two reports on SHS and respiratory problems among adult smokers. Both studies were from the USA and neither demonstrated significant relationships. ${ }^{45}$ The objective of this study was to investigate the association between SHS exposure in current active smokers and acute respiratory health problems and related ambulatory service utilisation during the previous two weeks.

\section{METHODS \\ Subjects}

A total of 11038 uniformed officers in the traffic, foot patrol, and marine formations of the Hong Kong Police Force were invited to participate in a health survey commissioned by the senior management of the force. During December 1995 to January 1996, the subjects completed a self administered structured questionnaire under classroom conditions. The questionnaire covered demographic characteristics, history of occupational exposure before their employment with the force, smoking habits, exposure to SHS at home and at work, and utilisation of ambulatory health care services in the previous 14 days. Respiratory symptoms were elicited using the UK Medical
Research Council respiratory health questionnaire ${ }^{6}$ Completed questionnaires were put into envelopes, sealed, and returned to the investigators at the end of each session. The subjects were reassured that no one, including their seniors and peers in the force, other than designated researchers in the University Department of Community Medicine, would be permitted access to the identity of individual subjects and that confidentiality was guaranteed. A total of 9923 officers participated with a response rate of $90 \%$, of whom 4102 were current smokers. Because of the much lower prevalence $(12.3 \%, \mathrm{n}=103)$ of female smokers only the 3999 male current smokers were included in this analysis. The data on 4468 male never-smokers were also analysed and compared to the current smokers.

\section{SHS exposure measurements and health outcomes}

The dependent variables for respiratory symptoms are throat problems, cough (or phlegm) in the morning, cough (or phlegm) during day/night, chronic cough (or phlegm), any cough or phlegm, increased cough and phlegm, ever wheezing, blocked/running nose, and any respiratory symptoms. Utilisation of outpatient health services during the past 14 days was assessed by doctor consultation for respiratory symptoms. The definitions of these variables have been reported in the previous publication. ${ }^{7}$

A current smoker was defined as one who currently and during the previous six months smoked at least one cigarette a day (or one cigar a week or an ounce of tobacco a month). Although our focus of investigation was the effects of SHS on current active smokers, never-smokers were also analysed for the purpose of comparison. Exposure to SHS at home was defined by the presence of one or more smokers who lived in the same household as the subject. Exposure to SHS at work was defined by the presence of one or more co-workers who smoked nearby in the same room each day.

Cigarette-hours is computed by multiplying the average number of cigarettes smoked by co-workers per hour to 
which subjects were exposed in the workplace by eight hours, which is the notional number of working hours per day.

\section{Statistical analysis}

In comparing the effects of SHS exposure at work and/or at home, on respiratory symptoms, multivariable logistic regression was used to calculate odds ratios (OR) with 95\% confidence intervals (CI), adjusted for age, marital status, educational attainment, police rank, type of duties (that is, traffic police, foot patrol, or marine police), exposure to a self perceived dusty or polluted environment in previous jobs, and SHS exposure at home or at work. Additional adjustment for amount of cigarette smoking (that is, 1-10, 11-20, 21-30, $\geqslant 30$ cigarettes per day) and duration of smoking (that is, $<5,5$ to $<10,10$ to $<15,15+$ years) was made in current smokers, and also for smoking status in the analysis of smokers and never-smokers combined. To examine further whether or not the effects of SHS exposure in current smokers and never-smokers were similar, interaction terms for SHS exposure and smoking status (that is, current smokers $v$ never-smokers) were fitted in the logistic regression model. A significant interaction term indicated a differential SHS effect. The analysis was performed using STATA version 8.0. ${ }^{8}$

\section{RESULTS}

The analysis of never-smokers had been published previously ${ }^{7}$; only part of the results on never-smokers (that is, SHS prevalence and adjusted odds ratios) were repeated in tables 2-4.

The demographic characteristics and SHS exposure patterns in current smokers are summarised in table 1. Only $12.5 \%$ were not exposed at home or at work and 5\% were exposed at home only. About half (53\%) were exposed at work only, and $30 \%$ were exposed at home and at work. One third $(33 \%)$ were exposed to four or more smoking coworkers, indicating that work exposure was much heavier than exposure at home where only $1.3 \%$ were exposed to four or more smokers.

Smokers had higher prevalence ratios for respiratory symptoms than never-smokers regardless of SHS exposure, but physician consultation and medication prevalence ratios were similar (table 2). The prevalence ratios for most respiratory symptoms were higher among those exposed to SHS at home, with adjusted odds ratios reaching 1.33 (95\% CI 1.12 to 1.59) for any symptoms (table 2 ). For SHS exposure at work, all the odds ratios for symptoms and physician consultation were highly significant and higher than those for home exposure. The highest, for chronic cough, was 2.52 (95\% CI 1.54 to 4.13 ), and for any symptoms, 1.66 (95\% CI 1.36 to 2.02 ).

We found significant dose-response relationships between all the outcome measures and the number of smokers at work, except for nasal problems (table 3). For those who were exposed to four or more smokers, the odds ratio for chronic cough was 3.02 (95\% CI 1.80 to 5.06). There were also significant trends for all outcome measures with the daily amount of exposure as stratified by cigarette-hours (table 4).

For SHS exposure at home, significant trends with the number of smokers at home were found for eight out of the 15 outcome measures (table 5 ).

The adjusted odds ratios for the effects of SHS exposure on current smokers were similar to those for never-smokers. Moreover, most of the interaction terms for SHS exposure variables and smoking status (that is, current smokers $v$ never-smokers) were not significant, indicating that the magnitude of the effects of SHS exposure on current smokers and never-smokers were similar.

To explore further the possibility of residual confounding in smokers due to their daily cigarette consumption, the
Table 1 Demographic characteristics and secondhand smoke (SHS) exposure in 3999 male current smokers in the Hong Kong Police

\begin{tabular}{|c|c|c|}
\hline Characteristics & No. & $\%$ \\
\hline \multicolumn{3}{|l|}{ Age (years) } \\
\hline$\leqslant 24$ & 844 & 21.1 \\
\hline $25-29$ & 1059 & 26.5 \\
\hline $30-34$ & 789 & 19.8 \\
\hline $35-39$ & 575 & 14.4 \\
\hline$\geqslant 40$ & 724 & 18.1 \\
\hline \multicolumn{3}{|l|}{ Marital status } \\
\hline Single & 1796 & 45.3 \\
\hline Married & 2054 & 51.8 \\
\hline Other & 113 & 2.9 \\
\hline \multicolumn{3}{|l|}{ Educational attainment } \\
\hline Grade 10 or below & 809 & 20.8 \\
\hline Grade 11 & 2891 & 74.5 \\
\hline Grades 12-13 & 139 & 3.6 \\
\hline Post-secondary & 43 & 1.1 \\
\hline \multicolumn{3}{|l|}{ Police rank } \\
\hline Police constable & 3248 & 81.6 \\
\hline Sergeant or senior sergeant & 638 & 16.0 \\
\hline Inspector or above & 96 & 2.4 \\
\hline \multicolumn{3}{|l|}{ Type of police } \\
\hline Traffic police & 548 & 13.8 \\
\hline Foot patrol & 2767 & 69.5 \\
\hline Marine police & 664 & 16.7 \\
\hline \multicolumn{3}{|c|}{$\begin{array}{l}\text { Worked in self perceived dusty or polluted } \\
\text { environment before }\end{array}$} \\
\hline No & 3417 & 86.7 \\
\hline Yes & 526 & 13.3 \\
\hline \multicolumn{3}{|c|}{ Daily amount of cigarette consumption (cigarettes) } \\
\hline $1-10$ & 1058 & 27.4 \\
\hline $11-20$ & 1940 & 50.2 \\
\hline $21-30$ & 331 & 8.6 \\
\hline$>30$ & 538 & 13.9 \\
\hline \multicolumn{3}{|c|}{ Duration of cigarette smoking (years) } \\
\hline$<5$ & 681 & 17.4 \\
\hline 5 to $<10$ & 1170 & 29.8 \\
\hline 10 to $<15$ & 920 & 23.4 \\
\hline $15+$ & 1155 & 29.4 \\
\hline \multicolumn{3}{|l|}{ SHS exposure* } \\
\hline None & 482 & 12.5 \\
\hline At home only & 194 & 5.0 \\
\hline At work only & 2047 & 52.9 \\
\hline At home and at work & 1146 & 29.6 \\
\hline \multicolumn{3}{|c|}{ Total number of smokers at home and at workt } \\
\hline 0 & 482 & 12.6 \\
\hline 1 & 446 & 11.6 \\
\hline $2-3$ & 1291 & 33.7 \\
\hline $4-5$ & 695 & 18.1 \\
\hline$\geqslant 6$ & 921 & 24.0 \\
\hline \multicolumn{3}{|c|}{ Number of co-workers smoking nearby at work $†$} \\
\hline 0 & 688 & 17.7 \\
\hline 1 & 475 & 12.2 \\
\hline 2 & 662 & 17.0 \\
\hline 3 & 769 & 19.8 \\
\hline$\geqslant 4$ & 1294 & 33.3 \\
\hline \multicolumn{3}{|l|}{ Number of smokers at homet } \\
\hline 0 & 2559 & 65.3 \\
\hline 1 & 949 & 24.2 \\
\hline 2 & 268 & 6.8 \\
\hline 3 & 90 & 2.3 \\
\hline$\geqslant 4$ & 50 & 1.3 \\
\hline \multicolumn{3}{|c|}{$\begin{array}{l}\text { Daily amount of SHS exposure at work, number of } \\
\text { cigarette-hours } \ddagger\end{array}$} \\
\hline 0 & 688 & 17.6 \\
\hline$\leqslant 4$ & 789 & 20.2 \\
\hline $4-16$ & 767 & 19.6 \\
\hline$>16-48$ & 793 & 20.3 \\
\hline$>48$ & 873 & 22.3 \\
\hline \multicolumn{3}{|c|}{$\begin{array}{l}\text { Missing data were excluded. } \\
\text { *Excluding self-exposure. } \\
\text { †Excluding self. } \\
\text { †Cigarette-hours were calculated by multiplying the average number of } \\
\text { cigarettes smoked by co-workers per hour to which subjects were } \\
\text { exposed in the workplace by } 8 \text { hours, which is the notional number of } \\
\text { working hours per day. }\end{array}$} \\
\hline
\end{tabular}


Table 2 Adjusted odds ratios for respiratory symptoms and physician consultations by source of secondhand smoke exposures in males

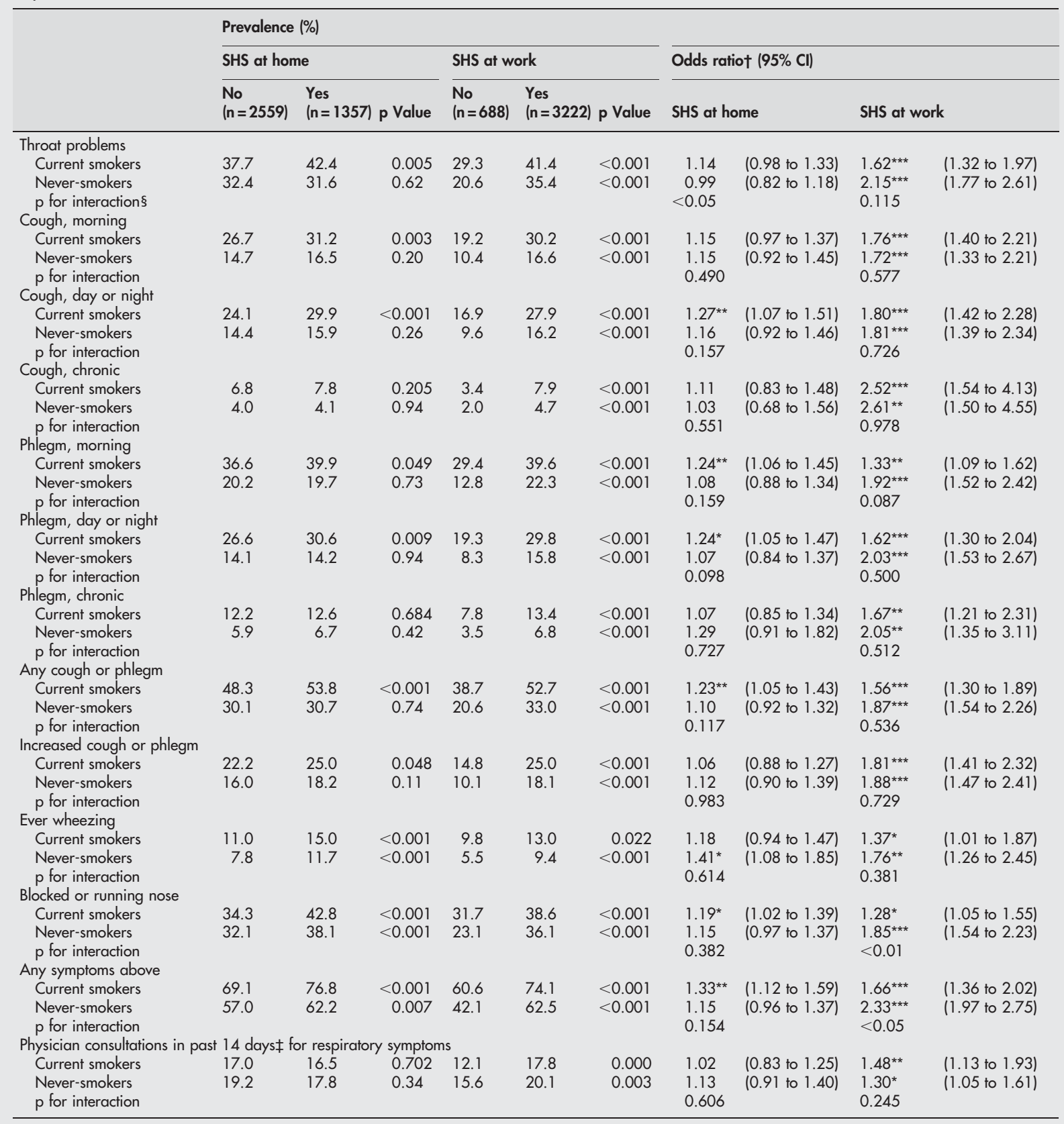

${ }^{*} \mathrm{p}<0.05 ;{ }^{* *} \mathrm{p}<0.01 ;{ }^{* * *} \mathrm{p}<0.001$

tOdds ratios are adjusted for age, marital status, educational attainment, police rank, type of police duties, exposure to self perceived dusty or polluted environment in previous job, and other SHS exposure. Additional adjustment for amount of smoking and duration of smoking was made in current smokers, and for smoking status in the analysis of current smokers and never-smokers combined.

¥Western physicians and Chinese traditional doctors

$\S p$ for interaction for SHS exposure variables and smoking status. A significant p value indicates significant difference in odds ratios between current smokers and never-smokers.

Odds ratios, adjusted for the variables above, except for SHS, for the top 12 items of respiratory symptoms in all current versus all never-smokers ranged from $1.09(95 \% \mathrm{Cl} 0.99$ to 1.20$)$ for blocked nose to $2.50(95 \% \mathrm{Cl} 2.25$ to 2.78$)$ for morning phlegm. The details are not shown here but are available from the authors. Adjusted odds ratio for the bottom three items were near unity $(\mathrm{p}>0.05)$.

analysis was stratified by daily smoking amount (that is, $1-10,11-20$, and $>30$ cigarettes) (results not shown in the tables). Strong and consistent effects of SHS were still observed, with all significant odds ratios being greater than unity in the three categories of smokers (see appendix: to view appendix visit the Tobacco Control website-http:// www.tobaccocontrol.com/supplemental).

\section{DISCUSSION}

In a probability sample survey of nine neighbourhoods in Philadelphia, Dayal et $a l^{4}$ did not find that greater SHS exposure $(\leqslant 1$ pack/day $v>1$ pack/day) was associated with more obstructive respiratory conditions among current smokers. The researchers did not allow for a category of no SHS exposure because all smokers were assumed to be 
Table 3 Adjusted odds ratios for respiratory symptoms and physician consultations by number of smokers at work in males

\begin{tabular}{|c|c|c|c|c|c|c|c|c|}
\hline & 1 smoke & ORt $(95 \% \mathrm{Cl})$ & 2 smoke & 5 OR† $(95 \% \mathrm{Cl})$ & 3 smokers & OR† $(95 \% \mathrm{Cl})$ & $\geqslant 4$ smokers OR† $(95 \% \mathrm{Cl})$ & $\begin{array}{l}p \text { for linear } \\
\text { trend }\end{array}$ \\
\hline \multicolumn{9}{|l|}{ Throat problems } \\
\hline Current smokers & $1.52^{* *}$ & (1.16 to 1.99 ) & $1.53^{* * *}$ & (1.19 to 1.97$)$ & $1.63^{* * *}$ & (1.28 to 2.07$)$ & $1.73^{* * *}(1.39$ to 2.16$)$ & $<0.001$ \\
\hline $\begin{array}{l}\text { Never-smokers } \\
\text { p for interaction§ }\end{array}$ & $\begin{array}{l}1.48^{* *} \\
0.702\end{array}$ & $(1.12$ to 1.96$)$ & $\begin{array}{l}1.98^{* * *} \\
0.203\end{array}$ & $(1.56$ to 2.51$)$ & $\begin{array}{l}2.08^{* * *} \\
0.393\end{array}$ & (1.64 to 2.62$)$ & $\begin{aligned} & 2.62^{\star * *} \quad(2.12 \text { to } 3.24) \\
<0.05 & \end{aligned}$ & $<0.001$ \\
\hline \multicolumn{9}{|l|}{ Cough, morning } \\
\hline Current smokers & $1.37^{*}$ & (1.01 to 1.87$)$ & $1.63^{* * *}$ & (1.23 to 2.16$)$ & $1.73^{* * *}$ & (1.32 to 2.27$)$ & $2.03^{* * *}(1.58$ to 2.61$)$ & $<0.001$ \\
\hline Never-smokers & $1.55^{\star}$ & (1.08 to 2.22 ) & $1.78^{* * *}$ & (1.31 to 2.43 ) & $1.69^{* *}$ & (1.24 to 2.29$)$ & $1.76^{* * *}(1.32$ to 2.33$)$ & $<0.001$ \\
\hline $\mathrm{p}$ for interaction & 0.743 & & 0.639 & & 0.599 & & 0.294 & \\
\hline \multicolumn{9}{|l|}{ Cough, day or night } \\
\hline Current smokers & $1.40^{*}$ & (1.02 to 1.93 ) & $1.66^{* * *}$ & (1.24 to 2.23 ) & $1.84^{* \star \star}$ & (1.39 to 2.43 ) & $2.03^{* * *}(1.57$ to 2.63$)$ & $<0.001$ \\
\hline Never-smokers & $1.46^{*}$ & (1.01 to 2.11$)$ & $1.77^{\star \star *}$ & (1.29 to 2.43 ) & $1.74^{\star \star *}$ & (1.27 to 2.37 ) & $1.99^{* * *}(1.50$ to 2.65$)$ & $<0.001$ \\
\hline $\mathrm{p}$ for interaction & 0.927 & & 0.893 & & 0.536 & & 0.679 & \\
\hline \multicolumn{9}{|l|}{ Cough, chronic } \\
\hline Current smokers & $2.26^{* *}$ & (1.24 to 4.15$)$ & $1.90^{*}$ & (1.06 to 3.42 ) & $2.45^{\star *}$ & (1.41 to 4.26$)$ & $3.02^{* * *}(1.80$ to 5.06$)$ & $<0.001$ \\
\hline Never-smokers & $2.10^{*}$ & (1.01 to 4.37 ) & $2.22^{*}$ & (1.16 to 4.27$)$ & $2.62^{* *}$ & (1.40 to 4.92$)$ & $3.02^{* * *}(1.68$ to 5.44$)$ & $<0.001$ \\
\hline$p$ for interaction & 0.790 & & 0.845 & & 0.939 & & 0.850 & \\
\hline \multicolumn{9}{|l|}{ Phlegm, morning } \\
\hline Current smokers & 1.12 & (0.85 to 1.47$)$ & 1.26 & (0.98 to 1.61$)$ & $1.28^{*}$ & (1.01 to 1.63 ) & $1.47^{* * *}(1.18$ to 1.83$)$ & $<0.001$ \\
\hline Never-smokers & 1.36 & (0.97 to 1.91$)$ & $1.91^{* * *}$ & (1.44 to 2.53 ) & $1.94^{\star * *}$ & (1.47 to 2.55 ) & $2.15^{* * *}(1.67$ to 2.77$)$ & $<0.001$ \\
\hline$p$ for interaction & 0.549 & & 0.058 & & 0.067 & & 0.070 & \\
\hline \multicolumn{9}{|l|}{ Phlegm, day or night } \\
\hline Current smokers & $1.43^{*}$ & (1.06 to 1.94$)$ & $1.71^{* * *}$ & (1.29 to 2.25$)$ & $1.65^{\star * *}$ & (1.26 to 2.16$)$ & $1.64^{* * *}(1.28$ to 2.10$)$ & $<0.001$ \\
\hline Never-smokers & 1.25 & (0.83 to 1.89$)$ & $1.93^{* * *}$ & (1.38 to 2.69$)$ & $1.93^{* * *}$ & (1.39 to 2.68$)$ & $2.47^{* * *} \quad(1.83$ to 3.34$)$ & $<0.001$ \\
\hline$p$ for interaction & 0.471 & & 0.780 & & 0.715 & & 0.105 & \\
\hline \multicolumn{9}{|l|}{ Phlegm, chronic } \\
\hline Current smokers & 1.27 & (0.82 to 1.98$)$ & 1.48 & (0.99 to 2.19$)$ & $1.48^{*}$ & (1.01 to 2.16$)$ & $2.04^{* * *}(1.44$ to 2.88$)$ & $<0.001$ \\
\hline Never-smokers & 0.89 & (0.45 to 1.75$)$ & $2.01^{* *}$ & (1.23 to 3.29 ) & 1.60 & (0.97 to 2.65$)$ & $2.83^{* * *}(1.82$ to 4.40$)$ & $<0.001$ \\
\hline$p$ for interaction & 0.382 & & 0.342 & & 0.831 & & 0.327 & \\
\hline \multicolumn{9}{|l|}{ Any cough or phlegm } \\
\hline Current smokers & 1.27 & (0.98 to 1.65$)$ & $1.54^{* * *}$ & (1.21 to 1.96$)$ & $1.58^{* * *}$ & (1.25 to 1.98$)$ & $1.69^{* * *}(1.37$ to 2.09$)$ & $<0.001$ \\
\hline Never-smokers & $1.34^{*}$ & (1.01 to 1.77$)$ & $1.92^{* * *}$ & (1.51 to 2.43 ) & $1.80^{* * *}$ & (1.43 to 2.28$)$ & $2.09^{* * *}(1.69$ to 2.59$)$ & $<0.001$ \\
\hline$p$ for interaction & 0.983 & & 0.339 & & 0.718 & & 0.344 & \\
\hline \multicolumn{9}{|c|}{ Increased cough or phlegm } \\
\hline Current smokers & $1.53^{*}$ & (1.09 to 2.13 ) & $1.71^{* * *}$ & (1.26 to 2.32$)$ & $1.78^{* * *}$ & (1.32 to 2.39 ) & $1.96^{* * *}(1.49$ to 2.57$)$ & $<0.001$ \\
\hline Never-smokers & $1.56^{*}$ & (1.10 to 2.21$)$ & $1.57^{* *}$ & (1.15 to 2.13$)$ & $1.95^{* * *}$ & (1.45 to 2.62$)$ & $2.18^{* * *}(1.67$ to 2.85$)$ & $<0.001$ \\
\hline$p$ for interaction & 0.804 & & 0.356 & & 0.902 & & 0.993 & \\
\hline \multicolumn{9}{|l|}{ Ever wheezing } \\
\hline Current smokers & 1.29 & (0.86 to 1.96$)$ & 1.24 & (0.84 to 1.82$)$ & 1.26 & (0.87 to 1.83$)$ & (1.09 to 2.13$)$ & $<0.05$ \\
\hline Never-smokers & 1.58 & (0.99 to 2.51$)$ & $1.66^{*}$ & (1.10 to 2.50$)$ & $1.97^{* *}$ & (1.33 to 2.91$)$ & (1.21 to 2.51$)$ & $<0.01$ \\
\hline$p$ for interaction & 0.380 & & 0.414 & & 0.139 & & 0.651 & \\
\hline \multicolumn{9}{|c|}{ Blocked or running nose } \\
\hline Current smokers & $1.32^{*}$ & (1.01 to 1.72$)$ & $1.44^{* *}$ & (1.13 to 1.84$)$ & 1.22 & (0.96 to 1.54$)$ & $1.21 \quad(0.98$ to 1.51$)$ & 0.340 \\
\hline Never-smokers & $1.51^{* *}$ & (1.15 to 1.98$)$ & $1.75^{\star * *}$ & (1.39 to 2.21 ) & $1.82^{* * *}$ & (1.45 to 2.29$)$ & $2.07^{* * *}(1.69$ to 2.55$)$ & $<0.001$ \\
\hline $\mathrm{p}$ for interaction & 0.450 & & 0.236 & & $<0.05$ & & $<0.001$ & \\
\hline \multicolumn{9}{|l|}{ Any symptoms above } \\
\hline Current smokers & $1.48^{\star *}$ & (1.12 to 1.96$)$ & $1.76^{* * *}$ & (1.35 to 2.29$)$ & $1.58^{* * *}$ & (1.23 to 2.02$)$ & $1.73^{* * *}(1.38$ to 2.17$)$ & $<0.001$ \\
\hline Never-smokers & $1.79 * * *$ & (1.39 to 2.30$)$ & $2.17^{* \star *}$ & $(1.75$ to 2.70$)$ & $2.28^{\star \star *}$ & (1.84 to 2.82$)$ & $2.73^{\star * *}(2.25$ to 3.31$)$ & $<0.001$ \\
\hline$p$ for interaction & 0.353 & & 0.384 & & 0.096 & & $<0.05$ & \\
\hline \multicolumn{9}{|c|}{ Physician consultations in past 14 days for respiratory symptoms $\ddagger$} \\
\hline Current smokers & $1.55^{*}$ & $(1.09$ to 2.20$)$ & $1.48^{*}$ & (1.06 to 2.05$)$ & $1.48^{*}$ & (1.08 to 2.03$)$ & (1.10 to 1.98$)$ & 0.051 \\
\hline Never-smokers & 1.13 & (0.82 to 1.56$)$ & 1.17 & (0.89 to 1.53$)$ & $1.32^{*}$ & (1.01 to 1.72$)$ & (1.11 to 1.80$)$ & $<0.01$ \\
\hline $\mathrm{p}$ for interaction & 0.123 & & 0.189 & & 0.412 & & 0.489 & \\
\hline \multicolumn{9}{|c|}{$\begin{array}{l}{ }^{*} \mathrm{p}<0.05 ;{ }^{* *} \mathrm{p}<0.01 ;{ }^{* *} \mathrm{p}<0.001 \text {. } \\
\text { †Within each smoking category, the reference group is current smokers with no co-workers smoking nearby at work; odds ratios are adjusted for age, marital } \\
\text { status, educational attainment, police rank, type of police duties, exposure to self perceived dusty or polluted environment in previous job, and SHS exposure at } \\
\text { home. Additional adjustment for amount of smoking and duration of smoking was made in current smokers, and for smoking status in the analysis of current } \\
\text { smokers and never-smokers combined. } \\
\text { †Western physicians and Chinese traditional doctors } \\
\text { §p for interaction for SHS exposure variables and smoking status. A significant } \mathrm{p} \text { value indicates significant difference in odds ratios between current smokers and } \\
\text { never-smokers. }\end{array}$} \\
\hline
\end{tabular}

exposed to SHS. In addition, the prevalence estimates in the report were not adjusted for potential confounders. On the other hand, from the National Health Interview Survey, Mannino et al ${ }^{5}$ reported that US current smokers with SHS exposure at home or at work (defined using dichotomised measures) were more likely to have reported an exacerbation of chronic respiratory disease in the two weeks preceding the survey than those not exposed to SHS, but the differences were not significant. A possible reason for the null or nonsignificant positive findings in the two studies may be due to the fairly crude way of measuring and defining SHS exposure using dichotomous variables. In contrast, we used the number of workers smoking nearby and the amount they smoked to quantify SHS exposure more sensitively. With a more accurate SHS exposure proxy allowing more precise measurement of risk, we had greater statistical power to detect the excess risk.

Eisner et al investigated the effect of SHS exposure on respiratory health before and after legislative prohibition of smoking in all bars and taverns by the state of California. During the follow up period, no overall change in daily cigarette consumption was observed in the current smoking bartenders. Of these, $63 \%$ of the symptomatic smokers no longer reported any respiratory symptoms after prohibition of smoking in their workplaces. This natural experiment has provided indirect evidence that the SHS exposure can 
Table 4 Adjusted odds ratios for respiratory symptoms and physician consultations by daily amount of SHS exposure (cigarette-hours) $\uparrow$ at work in males

\begin{tabular}{|c|c|c|c|c|c|c|c|c|c|}
\hline \multirow{2}{*}{ Throat problems } & \multicolumn{2}{|c|}{$\begin{array}{l}\leqslant 4 \text { cigarette-hours OR† } \\
(95 \% \mathrm{Cl})\end{array}$} & \multicolumn{2}{|c|}{$\begin{array}{l}>4 \text { to } 16 \text { cigarette-hours } \\
\text { OR† }(95 \% \mathrm{Cl})\end{array}$} & \multicolumn{2}{|c|}{$\begin{array}{l}>16 \text { to } 48 \text { cigarette-hours } \\
\text { OR† }(95 \% \mathrm{Cl})\end{array}$} & \multicolumn{2}{|c|}{$\begin{array}{l}>48 \text { cigarefte-hours } \\
\text { OR† }(95 \% \mathrm{Cl})\end{array}$} & \multirow[t]{2}{*}{$\begin{array}{l}\mathrm{p} \text { for linear } \\
\text { trend }\end{array}$} \\
\hline & & & & & & & & & \\
\hline Current smokers & $1.38^{* *}$ & (1.08 to 1.75$)$ & $1.39 * *$ & (1.09 to 1.77 ) & $1.96^{\star * *}$ & (1.55 to 2.49 ) & $1.79 * * *$ & (1.41 to 2.28 ) & $<0.001$ \\
\hline Never-smokers & $1.53^{* * *}$ & (1.21 to 1.92 ) & $2.04^{* * *}$ & (1.62 to 2.57 ) & $2.62^{* * *}$ & (2.07 to 3.32 ) & $2.79^{* * *}$ & (2.21 to 3.53$)$ & $<0.001$ \\
\hline$p$ for interaction§ & 0.675 & & 0.099 & & 0.245 & & $<0.05$ & & \\
\hline \multicolumn{10}{|l|}{ Cough, morning } \\
\hline Current smokers & 1.32 & (1.00 to 1.74$)$ & $1.69^{* \star *}$ & (1.29 to 2.22 ) & $2.02^{\star \star *}$ & (1.55 to 2.64 ) & $2.06^{* * *}$ & (1.57 to 2.69 ) & $<0.001$ \\
\hline Never-smokers & 1.17 & (0.85 to 1.59 ) & $1.72^{\star \star \star}$ & (1.27 to 2.33 ) & $2.12^{\star * *}$ & (1.56 to 2.87 ) & $2.10^{\star * *}$ & (1.55 to 2.85 ) & $<0.001$ \\
\hline $\mathrm{p}$ for interaction & 0.608 & & 0.806 & & 0.878 & & 0.793 & & \\
\hline \multicolumn{10}{|l|}{ Cough, day or night } \\
\hline Current smokers & 1.24 & $(0.93$ to 1.66$)$ & $1.70^{* \star *}$ & (1.28 to 2.25$)$ & $2.21^{* * *}$ & (1.68 to 2.91 ) & $2.14^{* * *}$ & (1.62 to 2.82 ) & $<0.001$ \\
\hline Never-smokers & 1.21 & (0.88 to 1.67$)$ & $1.84^{\star \star \star}$ & $(1.35$ to 2.49$)$ & $2.20^{\star * *}$ & (1.61 to 2.99 ) & $2.24^{* * *}$ & (1.65 to 3.04$)$ & $<0.001$ \\
\hline$p$ for interaction & 0.881 & & 0.977 & & 0.716 & & 0.812 & & \\
\hline \multicolumn{10}{|l|}{ Cough, chronic } \\
\hline Current smokers & $1.86^{*}$ & (1.04 to 3.30$)$ & $1.82^{*}$ & (1.02 to 3.23 ) & $2.76^{* * *}$ & (1.60 to 4.75$)$ & $3.69^{* * *}$ & $(2.16$ to 6.30$)$ & $<0.001$ \\
\hline Never-smokers & 1.45 & (0.74 to 2.83 ) & $2.76^{\star \star *}$ & (1.48 to 5.13 ) & $3.06^{* * *}$ & (1.63 to 5.74 ) & $3.58^{* * *}$ & (1.93 to 6.61 ) & $<0.001$ \\
\hline$p$ for interaction & 0.519 & & 0.339 & & 0.931 & & 0.698 & & \\
\hline \multicolumn{10}{|l|}{ Phlegm, morning } \\
\hline Current smokers & 1.00 & (0.79 to 1.28$)$ & 1.19 & (0.94 to 1.52$)$ & $1.52^{\star * *}$ & (1.20 to 1.93 ) & $1.66^{* * *}$ & (1.31 to 2.11$)$ & $<0.001$ \\
\hline Never-smokers & 1.27 & (0.95 to 1.68 ) & $1.73^{\star \star \star}$ & (1.31 to 2.28 ) & $2.23^{\star * *}$ & (1.69 to 2.95 ) & $2.83^{\star \star *}$ & (2.16 to 3.71 ) & $<0.001$ \\
\hline p for interaction & 0.216 & & 0.086 & & 0.092 & & $<0.05$ & & \\
\hline \multicolumn{10}{|l|}{ Phlegm, day or night } \\
\hline Current smokers & 1.10 & (0.83 to 1.46$)$ & $1.80^{* * *}$ & (1.38 to 2.35$)$ & $1.75^{\star * *}$ & (1.34 to 2.28 ) & $1.94^{* * *}$ & (1.49 to 2.53 ) & $<0.001$ \\
\hline Never-smokers & $1.42^{*}$ & (1.02 to 1.98 ) & $1.83^{\star \star \star}$ & (1.32 to 2.54 ) & $2.38^{\star * *}$ & (1.71 to 3.30$)$ & $2.77^{* * *}$ & (2.01 to 3.82 ) & $<0.001$ \\
\hline$p$ for interaction & 0.303 & & 0.885 & & 0.271 & & 0.304 & & \\
\hline \multicolumn{10}{|l|}{ Phlegm, chronic } \\
\hline Current smokers & 1.26 & (0.85 to 1.87$)$ & $1.56^{*}$ & (1.07 to 2.29 ) & $1.62^{*}$ & (1.11 to 2.36 ) & $2.24^{\star * *}$ & (1.56 to 3.22 ) & $<0.001$ \\
\hline Never-smokers & 1.09 & $(0.65$ to 1.85$)$ & 1.58 & $(0.96$ to 2.60$)$ & $2.64^{\star \star *}$ & (1.63 to 4.26 ) & $3.38^{* * *}$ & (2.13 to 5.38 ) & $<0.001$ \\
\hline $\mathrm{p}$ for interaction & 0.740 & & 0.864 & & 0.123 & & 0.372 & & \\
\hline \multicolumn{10}{|l|}{ Any cough or phlegm } \\
\hline Current smokers & 1.14 & (0.90 to 1.43$)$ & $1.60^{* * *}$ & (1.27 to 2.01 ) & $1.76^{* * *}$ & (1.40 to 2.21$)$ & $1.89^{* * *}$ & (1.50 to 2.38$)$ & $<0.001$ \\
\hline Never-smokers & 1.24 & $(0.98$ to 1.56$)$ & $1.77^{* * *}$ & (1.40 to 2.23 ) & $2.35^{\star \star \star}$ & (1.85 to 2.98 ) & $2.52^{\star * *}$ & (1.99 to 3.18 ) & $<0.001$ \\
\hline p for interaction & 0.625 & & 0.885 & & 0.184 & & 0.314 & & \\
\hline \multicolumn{10}{|c|}{ Increased cough or phlegm } \\
\hline Current smokers & $1.48^{*}$ & (1.10 to 2.00$)$ & $1.77^{\star \star *}$ & (1.31 to 2.38 ) & $1.99 * * *$ & (1.49 to 2.66 ) & $2.00^{* * *}$ & (1.50 to 2.68$)$ & $<0.001$ \\
\hline Never-smokers & 1.34 & $(0.99$ to 1.80$)$ & $1.92^{* \star *}$ & (1.44 to 2.57$)$ & $2.35^{\star \star *}$ & $(1.75$ to 3.15$)$ & $2.17^{\star * *}$ & (1.62 to 2.92$)$ & $<0.001$ \\
\hline$p$ for interaction & 0.441 & & 0.896 & & 0.752 & & 0.574 & & \\
\hline \multicolumn{10}{|l|}{ Ever wheezing } \\
\hline Current smokers & 1.16 & (0.80 to 1.69$)$ & 1.28 & (0.89 to 1.86$)$ & 1.41 & (0.98 to 2.02$)$ & $1.66^{* *}$ & (1.16 to 2.37$)$ & $<0.01$ \\
\hline Never-smokers & 1.28 & (0.85 to 1.91$)$ & $1.62^{*}$ & (1.09 to 2.41$)$ & $2.33^{\star * *}$ & (1.58 to 3.43 ) & $1.98^{* * *}$ & (1.34 to 2.93 ) & $<0.001$ \\
\hline $\mathrm{p}$ for interaction & 0.711 & & 0.467 & & 0.057 & & 0.589 & & \\
\hline \multicolumn{10}{|c|}{ Blocked or running nose } \\
\hline Current smokers & $1.31^{*}$ & (1.04 to 1.66$)$ & 1.07 & (0.84 to 1.35$)$ & $1.43^{\star *}$ & (1.13 to 1.80$)$ & $1.32^{*}$ & (1.04 to 1.67$)$ & $<0.05$ \\
\hline Never-smokers & $1.53^{\star \star \star}$ & (1.23 to 1.91$)$ & $1.81^{\star \star *}$ & (1.44 to 2.26 ) & $1.92^{\star * *}$ & (1.53 to 2.42 ) & $2.30^{\star * *}$ & (1.83 to 2.89 ) & $<0.001$ \\
\hline $\mathrm{p}$ for interaction & 0.218 & & $<0.01$ & & 0.060 & & $<0.01$ & & \\
\hline \multicolumn{10}{|l|}{ Any symptoms above } \\
\hline Current smokers & $1.41^{* *}$ & (1.11 to 1.80$)$ & $1.55^{\star * *}$ & (1.21 to 1.98$)$ & $1.92^{* * *}$ & (1.49 to 2.47 ) & $1.85^{\star * *}$ & (1.43 to 2.38 ) & $<0.001$ \\
\hline Never-smokers & $1.68^{* * *}$ & (1.37 to 2.06$)$ & $2.25^{\star \star *}$ & (1.82 to 2.78 ) & $2.74^{* * *}$ & (2.19 to 3.42 ) & $3.16^{* * *}$ & (2.53 to 3.95 ) & $<0.001$ \\
\hline$p$ for interaction & 0.186 & & 0.094 & & 0.080 & & $<0.05$ & & \\
\hline \multicolumn{10}{|c|}{ Physician consultations in past 14 days for respiratory symptoms $\ddagger$} \\
\hline Current smokers & $1.51^{* *}$ & (1.10 to 2.07$)$ & 1.36 & (0.98 to 1.88$)$ & $1.53^{* *}$ & (1.12 to 2.10$)$ & $1.51^{* *}$ & (1.10 to 2.07$)$ & $<0.05$ \\
\hline Never-smokers & 1.08 & (0.83 to 1.41$)$ & 1.21 & (0.93 to 1.58$)$ & $1.43^{* *}$ & (1.09 to 1.87$)$ & $1.55^{* * *}$ & (1.19 to 2.01$)$ & $<0.001$ \\
\hline p for interaction & 0.061 & & 0.540 & & 0.290 & & 0.803 & & \\
\hline
\end{tabular}

${ }^{*} \mathrm{p}<0.05 ;{ }^{* *} \mathrm{p}<0.01 ;{ }^{* * *} \mathrm{p}<0.001$.

WWithin each smoking category, the reference group is current smokers without SHS exposure nearby at work; odds ratios are adjusted for age, marital status, educational attainment, police rank, type of police duties, exposure to self perceived dusty or polluted environment in previous job, and SHS exposure at home. Additional adjustment for amount of smoking and duration of smoking was made in current smokers, and for smoking status in the analysis of current smokers and never-smokers combined.

$¥$ Western physicians and Chinese traditional doctors.

$\S p$ for interaction for SHS exposure variables and smoking status. A significant $p$ value indicates significant difference in odds ratios between current smokers and never-smokers.

- Cigarette-hours were calculated by multiplying exposure to average number of cigarettes smoked by co-workers nearby in one hour with 8 hours per day.

produce an adverse impact on respiratory health in current smokers. However, no dose response gradient was examined in that study.

Our study is the first to show strong and significant doseresponse relationships between SHS exposure at home and at work and acute and chronic respiratory symptoms, and physician consultation. It is biologically plausible that SHS can cause respiratory symptoms in active smokers as it causes such symptoms in non-smokers. There could be several reasons why previous studies did not find significant relationships. First, many studies on SHS were focused on non-smokers and the smokers were not asked about their SHS exposure. Second, the effects of active smoking may have been very strong and the level of SHS exposures either proportionately relatively low or not uniform across all subjects, so that the effects of SHS could not be separated from those of active smoking. Third, as smoke-free policies have become more common in western countries with more stringent tobacco control measures, fewer people smoke in the workplace and we would expect smokers to be less exposed to SHS from their co-workers, whereas Hong Kong has yet to outlaw smoking in the workplace, including 
Table 5 Adjusted odds ratios for respiratory symptoms and physician consultations by number of smokers at home in males

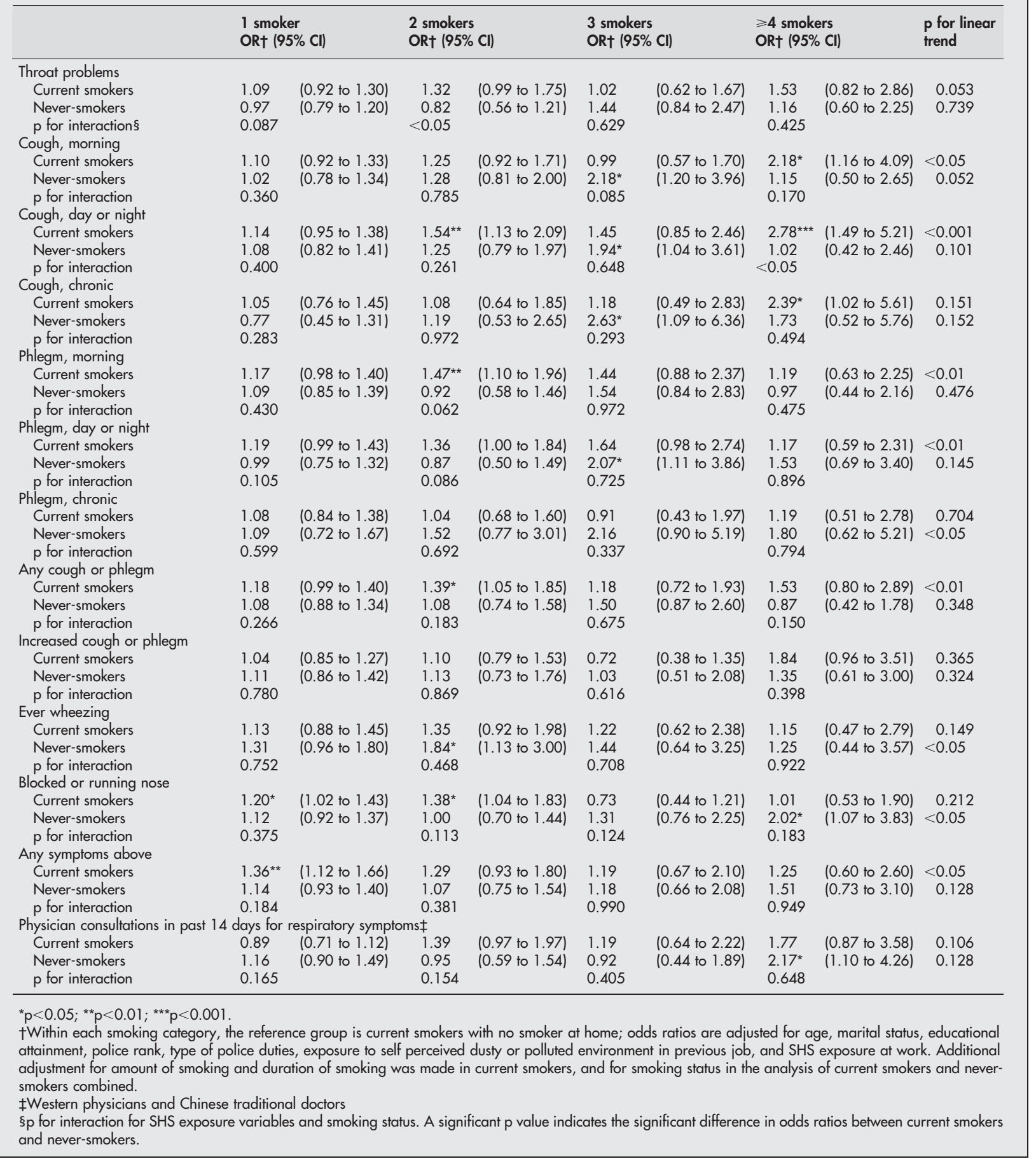

restaurants, bars and other public places. Fourth, if smokers are less aware of their SHS exposures, they might have under-reported exposure.

Among current smokers, all are in fact exposed to SHS. The distinction lies between exposure to smoke from their own cigarettes and smoke from other smokers' cigarettes. Although it is difficult to imagine in the real world any smoker not being exposed to smoke emitted from his or her cigarettes in between puffs, our calculation of the odds ratio of SHS in smokers was based on comparing the odds of respiratory symptoms who were not exposed to others' SHS with those who were, the amount of which depends on the number of smokers in the vicinity. Therefore our comparisons in respiratory symptoms were between "some exposure" (the reference category) and "greater amounts" (depending on numbers of smokers in the vicinity). SHS from smokers' own cigarettes may be qualitatively different from that caused by other peoples' smoking due to settling and aging of the smoke as it disperses. As a result, the true strength of association may be even greater than that reported.

The strength of the present study is that we used the same standardised structured questionnaire and asked the same questions on SHS exposure of all police officers, regardless of their smoking status. We asked objective questions on the number of smokers smoking at home and the number of coworkers who smoked nearby, and avoided the subjective 
interpretation of what constituted SHS exposure. In our previous report we demonstrated strong dose-response relationships between SHS and respiratory symptoms in never smokers. ${ }^{7}$ Similar dose-response gradients were also observed in active smokers in the present study. Furthermore, we found that the adjusted odds ratios in current smokers were similar to those in never smokers, as shown by the insignificant interaction terms for SHS exposure variables and smoking status. The similar effect size of SHS in both never and current smokers lends support to the validity of SHS measurement in our study.

In Hong Kong, as in mainland China and other countries in Asia, smoking is allowed in many workplaces and SHS exposure levels are higher than those in the USA and other western countries. In the workforce we studied (the Hong Kong Police), both smoking prevalence and SHS exposures among smokers were much higher than in the general population and provided a unique opportunity for the present enquiry to examine dose-response relationships.

Although misclassification of smokers as non-smokers has been used as an explanation for the observed association between SHS exposure and adverse health effects in nonsmokers, misclassification of non-smokers as smokers is very unlikely. We measured exhaled air carbon monoxide levels in a random sample of 110 male officers and found that 50 of 55 declared smokers had values $>10 \mathrm{ppm}$, but no subjects who declared they were non-smokers had values $>9 \mathrm{ppm}$. This suggested that reporting of smoking status among police officers was highly accurate and reliable. However, we acknowledge that our study could have been strengthened by more comprehensively and systematically validating SHS exposure status and intensity using biochemical measures, in addition to self reports. This, however, would be very difficult to distinguish from metabolites resulting from active smoking, unless radioactive traces were to be applied to the cigarettes smoked by the subjects ( $v$ non-radioactive labelled SHS) under trial conditions which would be prohibitively expensive and impractical. More realistically, environmental measures such as air nicotine levels in the workplace may be the best proxy feasible for future studies to confirm the present observations. ${ }^{10}$

The questions used for eliciting respiratory symptoms also appear to be valid. The odds ratios for all outcomes measures, except for nasal problem $(p=0.26)$ and physician consultation for respiratory symptoms $(p=0.20)$, were expectedly higher in current smokers than in non-smokers (table 2; $p$ value not shown). The adjusted odds ratios of respiratory symptoms in current smokers versus never-smokers, regardless of SHS exposure, ranged from 1.09 to 2.50 (table not shown), and were consistent with those from previous reports, all of which ignored SHS exposure. These suggest that although current smokers had poorer respiratory health than the non-smokers, the former did not necessarily use more health service, which is consistent with the pattern of health service utilisation in smokers reported elsewhere. ${ }^{11}{ }^{12}$

Smokers with respiratory symptoms may over-report SHS exposures but we believe this is also unlikely because awareness of the adverse effects of SHS among smokers was low (and much lower than the non-smokers) and very few smokers, if any, would have thought that their respiratory symptoms could be attributed to other people's smoking. The Dublin Healthy Cities project ${ }^{13}$ shows that smokers were less likely than nonsmokers to be bothered by SHS exposure (50\% v 92\%) and be aware that it was harmful to their health (59\% v 85\%). Knowledge about health risks of SHS was also lower in the Hong Kong general population. ${ }^{14}$ We also adjusted the risk estimates for the amount smoked by the smokers themselves as well as the total duration of smoking.

We acknowledge that the cross sectional design may first appear to be a potential limitation of this survey but a reverse

\section{What this paper adds}

In non-smokers, secondhand smoke (SHS) exposure has been shown to be a causal factor for heart disease, other cardiovascular abnormalities and lung cancer in adults, and respiratory ill health and cardiovascular abnormalities in children. Few studies have examined the adverse respiratory effects of SHS exposure among active smokers.

Smokers experience significant additional risks from SHS exposures. Strong dose-response relationships are found between SHS exposures, and respiratory symptoms and recent health care utilisation in active smokers.

The results of this study suggest that SHS exposure can also harm active smokers. These findings have important implications for the design and provision of smoking booths in restaurants, airports and other venues, in which concentrations of SHS are invariably high.

causal association, that of increasing respiratory symptoms leading to increasing SHS exposure, is highly doubtful, especially given our focus on acute respiratory symptoms and associated health services use in the previous 14 days. In fact, we believe that a cross sectional design is probably the only feasible and appropriate strategy in examining the acute harmful effects of SHS where a two week window would not be expected to induce an appreciable recall bias, and certainly not a systematic one. On the other hand, random misclassification would only have diluted the observed results. In addition, the strength of the relationship could have been underestimated because smokers who were less vulnerable to SHS could have survived in this work force which demands a high level of physical fitness. Moreover, given the high prevalence of smoking it is very likely that those who reported no exposure and were used as the reference group for odds ratio estimation could have been exposed and hence misclassified, resulting in underestimation of the risk. Residual confounding by some unknown factors cannot be totally ruled out despite our adjustment of many potential confounders, but it is difficult to conceive a confounder which can explain away the strong dose response relationships here.

There were no designated smoking or smoke-free areas with adequate enforcement, in the offices, transportation, or leisure areas used by the workforce in the present study. With a smoking prevalence of $28 \%$ among office workers in the USA, Repace et al ${ }^{10}$ estimated that $95 \%$ of non-smoking workers exceeded the level of $0.04 \mathrm{ng} / \mathrm{ml}$ of salivary cotinine, corresponding to one expected death from heart disease per 1000 workers at risk from passive smoking. ${ }^{10}$ This corresponds to the US Occupational Safety and Health Administration significant risk level. Virtually all workers in office workplaces with unrestricted smoking were estimated to exceed the de manifestis ( 1 expected death per 8000 exposed) level.

If the association we observed here is causal, the current focus on the prevention of harm caused by SHS to children and non-smokers should be extended to include smokers. More research is needed to examine whether SHS can have more serious health effects such as lung cancer and heart disease on smokers, as SHS can cause such diseases in nonsmokers. In smoking surveys, both smokers and nonsmokers should be asked about SHS exposures in the same standard way. Biochemical tests which can separate exposure to the toxic substances due to active smoking and passive smoking would be useful (but not yet available) to quantify the two exposures so that the two effects can be measured separately. We recognise that the best evidence that SHS can cause acute respiratory symptoms would have to come from experiments unethical by any criteria, involving exposure of 
smokers, while they are not smoking, to SHS in a gas chamber. However, it is difficult to envisage that if such experiments were done, the smokers would not feel any discomfort and would not report any symptoms after exposure to SHS, which can cause lung cancer, heart disease, and other health problems.

Under the existing legislation in Hong Kong, smoking is prohibited in some public indoor premises, such as cinemas, supermarkets, and shopping malls, but is allowed in most indoor workplaces, such as restaurants. In May 2005, the government proposed new legislation that the current ban should be extended to all indoor spaces, including restaurants, bars, and karaokes. The results of the present study provide a strong argument against the provision of separately ventilated areas because smokers in designated smoking areas are exposed to high levels of secondhand smoke which will cause additional harm to their health. Instead, the only effective public health approach is to impose a complete ban without exception or special provision.

\section{ACKNOWLEDGEMENTS}

We thank CM Wong, PhD, for research advice and assistance; ASM Abdullah, PhD, J Cheang, M Chi, D Ho, D Kwan, KW Lee and S Ma for data processing and field work. We gratefully acknowledged the invaluable comments of Dr Jonathan Samet.

\section{APPENDIX}

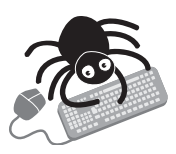

To view appendix visit the Tobacco Control websitehttp://www.tobaccocontrol.com/supplemental

\section{Authors' affiliations}

T-H Lam, L-M Ho, A J Hedley, R Fielding, S M McGhee, G M Leung, Department of Community Medicine, The University of Hong Kong, Hong Kong

P Adab, Department of Public Health and Epidemiology, The University of Birmingham, Birmingham, UK

L Aharonson-Daniel, Israel Center for Trauma and Emergency Medicine Research, The Gertner Institute for Epidemiology and Health Policy

Research, Sheba Medical Center, Tel Hashomer, Israel
Grant support: This study was support by grants from the Hong Kong Police Department and the Hong Kong Police Training School, Hong Kong Government.

Competing interests: none declared

\section{REFERENCES}

1 United States Environmental Protection Agency. Respiratory health effects of passive smoking: lung cancer and other disorders. Washington DC: US Environmental Protection Agency, 1992.

2 American College of Chest Physicians. American Thoracic Society, Asia Pacific Society of Respirology, Canadian Thoracic Society, European Respiratory Society, International Union Against Tuberculosis and Lung Disease. Smoking and health: a physician's responsibility. A statement of the joint committee on smoking and health. Monaldi Arch Chest Dis 1995;50:394-7.

3 Diethelm PA, Rielle JC, McKee M. The whole truth and nothing but the truth? The research that Philip Morris did not want you to see. Lancet 2004;365:number 9454, http://image.The Lancet.com/extras/ 03art7306web.pdf. (Accessed January 7, 2005).

4 Dayal HH, Khuder S, Sharrar R, et al. Passive smoking in obstructive respiratory disease in an industrialized urban population. Environ Res 1994;65:161-71.

5 Mannino DM, Siegel M, Rose D, et al. Environmental tobacco smoke exposure in the home and worksite and health effects in adults: results from the 1991 national health interview survey. Tobacco Control 1997;6:296-305.

6 Florey C du V, Leeder SR. Methods for cohort studies of chronic airflow limitation. Geneva, Switzerland: World Health Organization, 1982. European series No. 12. Publication MW 616.24 F63

7 Lam TH, Ho LM, Hedley AJ, et al. Environmental tobacco smoke exposure among police officers in Hong Kong. JAMA 2000;284:756-63.

8 STATA Corp. STATA statistical software [computer program] Release 8.0. College station, Texas: STATA Corp, 2003 http://www.stata.com (Accessed January 7, 2005)

9 Eisner MD, Smith AK, Blanc PD. Bartenders' respiratory health after establishment of smoke-free bars and taverns. JAMA 1998;280:1909-14.

10 Repace JL, Jinot J, Bayard S, et al. Air nicotine and saliva cotinine as indicators of workplace passive smoking exposure and risk. Risk Analysis 1998;18:71-83.

11 Vogt TM, Schweitzer SO. Medical costs of cigarette smoking in a health maintenance organization. Am J Epidemiol 1985;122:1060-6.

12 Lam TH, Leung GM, Ho LM. The effects of environmental tobacco smoke on health services utilization in the first eighteen months of life. Pediatrics 2001;107:E91.

13 Howell F, Doorley P. Employee attitudes to involuntary smoking at the workplace. Irish Medical Journal 1991;84(3):94-6.

14 Lam TH, Janghorbani M, Hedley AJ, et al. Public opinion on smoke-free policies in restaurants and predicted effect on patronage in Hong Kong. Tobacco Control 2002;11:195-200.

\section{The Lighter Side}

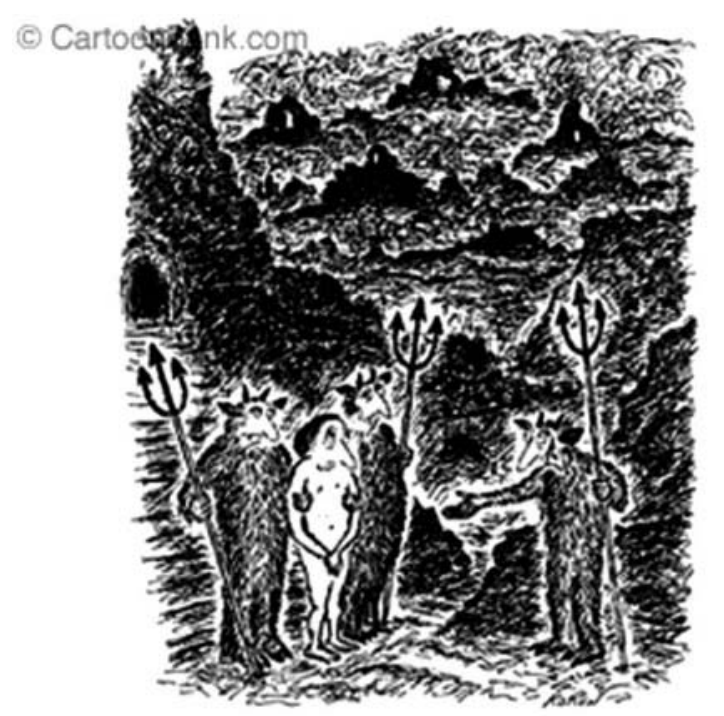

\section{"Hey, it's not all fire and brimstone anymore —one of our nine circles is even smoke-free."}

\footnotetext{
() The New Yorker Collection 2005 Edward Koren from Cartoonbank.com. All Rights Reserved.
} 